\title{
IDENTIFIKASI POTENSI HUTAN MANGROVE SEBAGAI PENGUAT KAWASAN EKOWISATA DI PESISIR BALE-BALE
}

\author{
Wenang Anurogo ${ }^{1}$, Muhammad Zainuddin Lubis ${ }^{2}$, Andi ${ }^{3}$ \\ ${ }^{1}$ Email: wenang@polibatam.ac.id \\ Teknik Geomatika Politeknik Negeri Batam \\ 2Email: zainuddinlubis@polibatam.ac.id \\ Teknik Geomatika Politeknik Negeri Batam \\ 33Email: andisurya@gmail.com \\ Teknik Geomatika, Politeknik Negeri Batam
}

\begin{abstract}
Technological advances in UAV (Unmanned Arial Vehicle) photogrammetry have been more efficient and accurate in the field of mapping and monitoring surveys. This study aims to determine the level of potential mangrove forests seen from the density of its vegetation, mangrove species and know how the relationship to marine biota contained in coastal areas bale-bale Batam. The recording data was taken on 26-08-2017. The method used to determine the density is the transformation of the NDVI vegetation index combined with the field transect. the field transect was conducted to see the species and biota of its association contained in each type of mangrove forest vegetation. The results of this study indicate that mangrove in coastal bale-bale has an area of 4.915 $\mathrm{Ha}$, with the potential of mangrove forest area is still in potential condition seen from the extraction vegetation density from the transformation of vegetation index used and with the identification of mangrove species that is Avecennia and Rhizopora, relationship with the type of biota association Ocypodidae, Coenobitadae, and Gobiidae especially for Rhizopora mangrove species, it is because rhizopora is the most dominant type of mangrove in the research location.
\end{abstract}

\begin{abstract}
Abstrak: Kemajuan teknologi dalam fotogrametri UAV (Unmanned Arial Vehicle) telah lebih efisien dan akurat di bidang pemetaan dan pemantauan survei. Penelitian ini bertujuan untuk mengetahui tingkat potensi hutan mangrove dilihat dari kepadatan vegetasinya, spesies mangrove dan mengetahui bagaimana hubungannya dengan biota laut yang terdapat di kawasan pesisir bale-bale Batam. Data rekaman diambil pada 26-08-2017. Metode yang digunakan untuk menentukan kepadatan adalah transformasi indeks vegetasi NDVI dikombinasikan dengan transek lapangan. transek lapangan dilakukan untuk melihat spesies dan biota dari keterkaitannya yang terkandung dalam setiap jenis vegetasi hutan mangrove. Hasil penelitian ini menunjukkan bahwa mangrove di pesisir bale-bale memiliki luas 4,915 $\mathrm{Ha}$, dengan potensi kawasan hutan mangrove masih dalam kondisi potensial dilihat dari ekstraksi kepadatan vegetasi dari transformasi indeks vegetasi yang digunakan dan dengan identifikasi Spesies mangrove yaitu Avecennia dan Rhizopora, hubungannya dengan jenis asosiasi biota Ocypodidae, Coenobitadae, dan Gobiidae terutama untuk spesies mangrove Rhizopora, karena rhizopora adalah jenis mangrove yang paling dominan di lokasi penelitian.
\end{abstract}

keywords: unmanned arial vehicle, vegetation index, tourism; mangrove, associate biota. 


\section{PENDAHULUAN}

Wilayah pesisir bale-bale yang terletak di kecamatan nongsa pulau batam merupakan salah satu kawasan dengan tutupan vegetasi mangrove yang cukup luas. kawasan mangrove dapat diidentifikasi dengan menggunakan teknologi penginderaan jauh, dimana letak geografi hutan mangrove yang berada pada daerah peralihan darat dan laut memberikan efek perekaman yang khas jika dibandingkan obyek vegetasi darat lainnya (Anurogo et al., 2005). Salah satu penginderaan jauh yang efisien serta akurat digunakan adalah fotogrametri jenis UAV (Anurogo et al, 2017).

Vegetasi umumnya bisa dideteksi dengan menggunakan transformasi indeks vegetasi (Danoedoro, 2012). Indeks vegetasi adalah merupakan suatu transformasi matematis yang melibatkan beberapa saluran sekaligus untuk menghasilkan citra baru yang lebih representatif dalam menyajikan aspek-aspek yang berkaitan dengan vegetasi (Danoedoro, 2012). Hasil citra indeks vegetasi dapat diolah lebih lanjut salah satu contohnya adalah penerapan metode transek garis.metode transek merupakan cara yang paling efektif mempelajari perubahan keadaan vegetasi menurut keadaan tanah, topografi, dan elevasi (Campbell, 2004). Sehingga metode transek juga dapat digunakan untuk mengidentifikasi jenis vegetasi ataupun jenis kehidupan habitat lainnya (Kuenzer et al 2011; Vo et al, 2013). Tujuan dari penelitian ini adalah untuk memperoleh informasi mengenai hubungan jenis vegetasi mangrove terhadap biota asosiasi di wilayah pesisir bale-bale dengan metode garis transek.

\section{METODE}

Data yang digunakan adalah hasil perekaman fototgrametri di pesisir bale-bale dengan resolusi $2 \mathrm{px} / \mathrm{ich}$ yang diambil pada tanggal 26-08-2017. Adapun Proses penelitian di sajikan dalam diagram alir gambar 1.

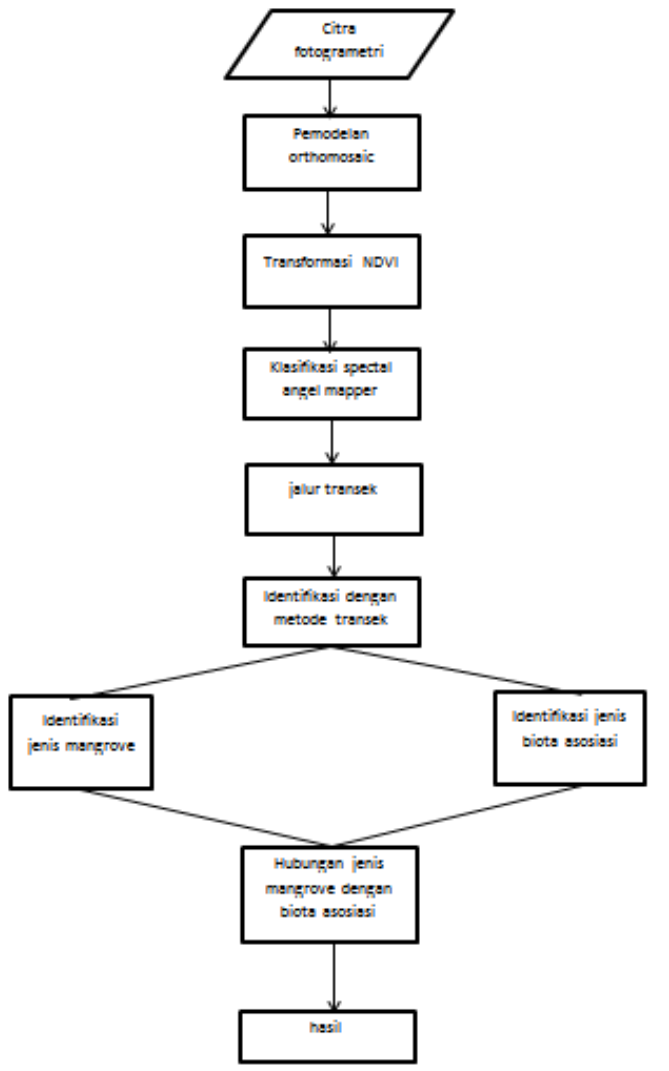

Gambar 1. Diagram alir penelitian

Kawasan wisata pantai bale-bale secara administrasi terletak di Pulau Batam Kota Batam Provinsi Kepuluan Riau dengan cakupan lokasi pada koordinat antara $\mathrm{X}$ : 397019 Y: 129634 sampai dengan X: 397220 Y: 129635 dengan koordinat Universal Transvers Mercator (UTM) Zona 48N selatan garis katulistiwa. Lokasi penelitian ditunjukkan pada gambar 2.

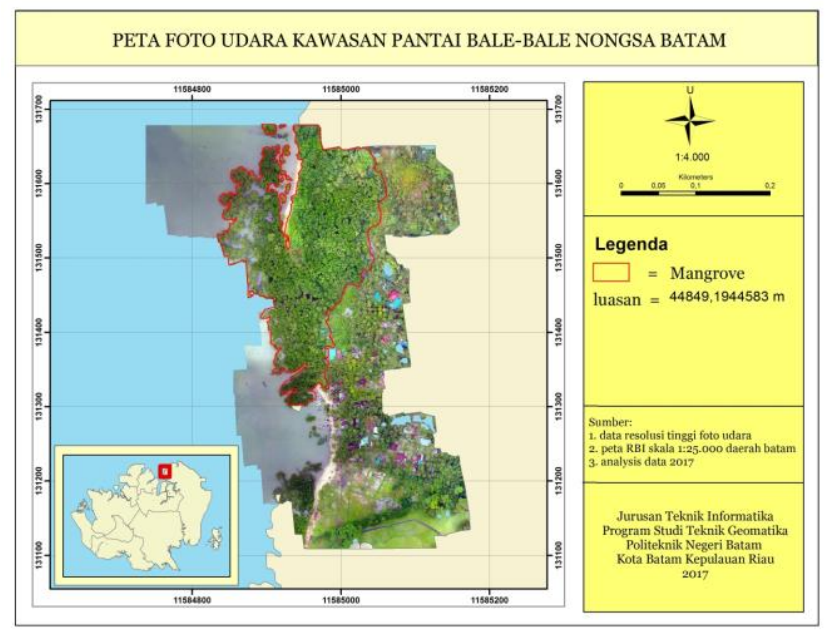

Gambar 2. Lokasi penelitian 


\section{Pemodelan Orthomosaic}

Pengolahan awal citra hasil perekaman fotogrametri yaitu pembuatan model orthomosaic. Software yang digunakan adalah software pemetaan fotogrametri. Proses pembentukan model orthomosaic meliputi align photo,built dense cloud,built mesh,dan built texture.

\section{Transformasi NDVI}

Indeks vegetasi atau NDVI adalah indeks yang menggambarkan tingkat kehijauan suatu tanaman. Indeks vegetasi merupakan kombinasi matematis antara band merah dan band NIR (Near-Infrared Radiation) yang telah lama digunakan sebagai indikator keberadaan dan kondisi vegetasi (Lillesand dan Kiefer 1997). Transformasi NDVI dalam penelitian ini digunakan untuk menentukan tingkat kerapatan vegetasi sehingga menjadi acuan dasar dalam klasifikasi algoritma spectral angel mapper adapun persamaan NDVI sebagai berikut (Lubis et al, 2017; Rizki et al 2017; Anurogo et al.2018):

\section{NDVI $=(\mathrm{NIR}-\mathrm{Red}) /(\mathrm{NIR}+\mathrm{Red})$ (1)}

Dimana NIR merupakan radiasi inframerah dekat dari piksel, dan Red merupakan radiasi cahaya merah dari piksel umum Nilai NDVI berkisar dari -1 (yang biasanya air) sampai +1 (vegetasi lebat).

Klasifikasi Algoritma Spectral Angel Mapper (SAM). Penerapan algoritma spectral angel mapper digunakan untuk klasifikasi tingkat kerapatan objek vegetasi serta untuk membedakan objek non vegetasi. Klasifikasi algoritma spectral angel mapper merupakan klasifikasi supervised dengan menghitung sudut antara kedua spektrum, dengan asumsi keduanya sebagai vektor dalam ruang dengan dimensi yang sama dengan jumlah saluran (Rashmi et al., 2014). Proses klasifikasi algoritma spectral angel mapper adalah sebagai berikut: region of interest objek vegetasi dan objek non vegetasI, klasifikasi berdasarkan warna, dan mengklasifikasikan hasil NDVI dengan menggunakan algoritma SAM. Algoritma Klasifikasi SAM menghasilkan kerapatan vegetasi mangrove, sehingga di peroleh dasar penentuan jenis mangrove.

\section{Penentuan Jalur Transek}

Pengamatan atau identifikasi dilakukan dengan metode transek dimana terdapat 10 transek garis yang di tarik berdasarkan hasil klasifikasi SAM. Adapun jalur transek ditampilkan pada gambar 3 .

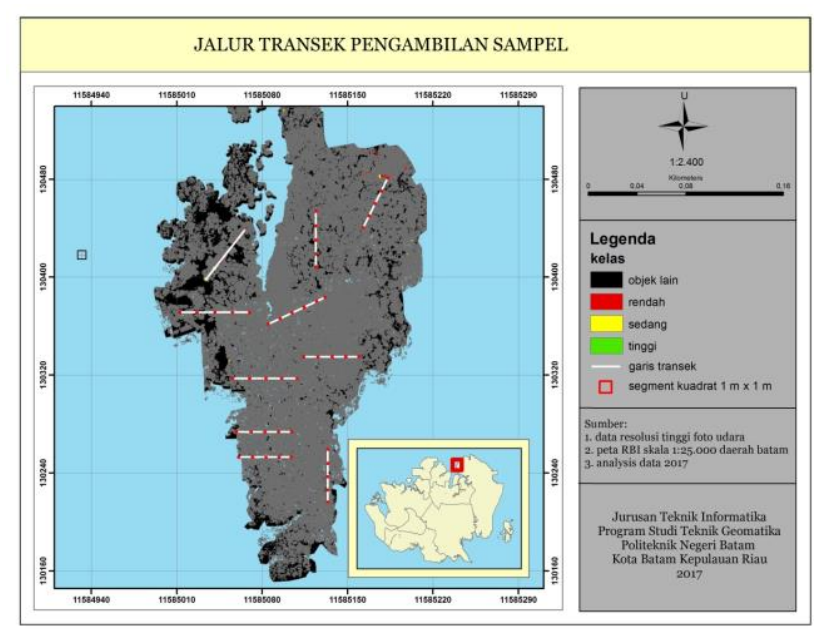

Gambar 3. Segmen transek penelitian

\section{HASIL DAN PEMBAHASAN}

Proses pengolahan citra fotogrametri dilakukan dalam beberapa tahap pemerosesan, proses awal pengolahan citra fotogrametri adalah dengan membentuk model orthomosaic.tujuan pembentukan Model orthomosaic adalah untuk mengoreksi kesalahan geometrik sehingga dapat digunakan untuk pengolahan lebih lanjut. Proses pembuatan model orthomosaic meliputi pembuatan dense point clouds, mesh dan digital elevation model (DEM).

Langkah selanjutnya dalam pemrosesan citra adalah dengan mendapatkan nilai indeks vegetasi. hasil transformasi NDVI menghasilkan citra dengan nilai digital (-0.16 - 0.32). Dari nilai tersebut dapat diasumsikan bahwa semakin tinggi nilai indeks maka semakin tinggi pula nilai kerapatan. kemudian hasil indeks tersebut diklasifikasikan berdasarkan nilai pantulan spektral terhadap objek vegetasi. Jenis pengklasifikasian yang digunakan adalah klasifikasi supervised yaitu algoritma Spectral Angel Mapper (SAM). Hasil klasifikasi algoritma SAM memberikan keterangan bahwa setiap kelas yang terbentuk mewakili obyek yang dominan dalam satu piksel dan dikatakan unclassified (tidak terkelaskan) jika tidak tergabung dalam satu kelas. 
Hasil identifikasi dilakukan dengan menggunakan metode transek. Jalur transek ditarik berdasarkan keanekaeragaman jenis vegetasi mangrove, ditinjau berdasarkan nilai hasil klasifikasi SAM (spectral angel mapper) asumsi dalam penentuan jenis adalah bahwa semakin rapat suatu tutupan vegetasi, maka keanekaragaman jenis akan semakin rendah begitu juga sebaliknya. pemebentukan jalur transek meliputi garis dan segmen-segmen dengan Luas segmen yaitu 2 x resolusi spasial. fotogrametri dji phantom 4 memiliki resolusi spasial $0.5 \times 0.5 \mathrm{~m}$ sehingga luas pada masingmasing segmen adalah $1 \times 1 \mathrm{~m}$. Terdapat 10 jalur transek dengan panjang masing-masing yaitu 50m. Salah satu transek ditampilkan pada gambar 4.

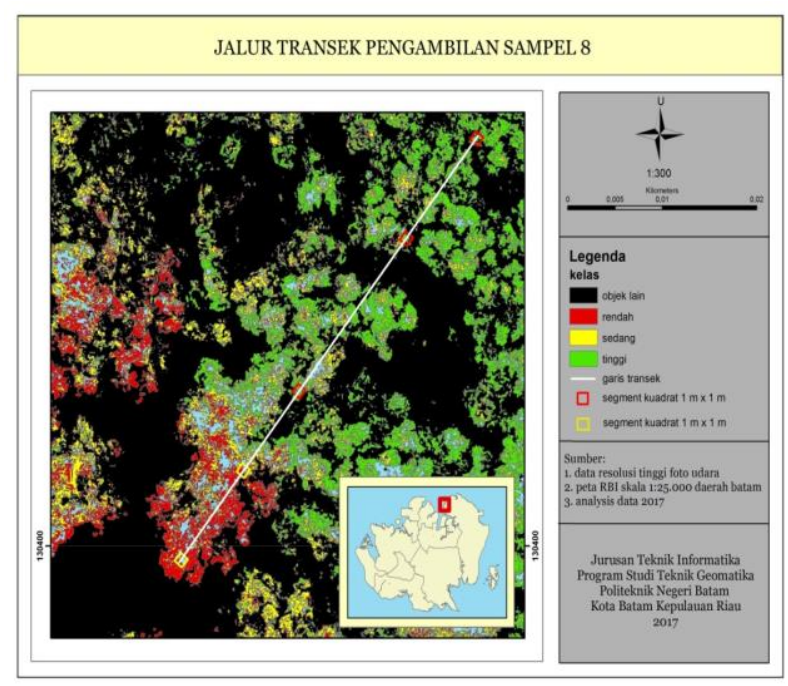

Gambar 4. Jalur transek sampel 8

Adapun Hasil identifikasi lapangan pada masing-masing jalur transek pada tabel 1 .

Tabel 1. Tabel hasil pengamatan

\begin{tabular}{lll}
\hline \multicolumn{3}{c}{ Tabel Hasil Pengamatan } \\
\hline $\begin{array}{l}\text { Jalur } \\
\text { Transek }\end{array}$ & $\begin{array}{l}\text { Jenis } \\
\text { Mangrove }\end{array}$ & $\begin{array}{l}\text { Jenis } \\
\text { Asosiasi }\end{array}$ \\
\hline Transek 1 & Rhizopora & Potamididae \\
\hline Transek 2 & Rhizopora & $\begin{array}{l}\text { Potamididae, } \\
\text { Acypopidae }\end{array}$ \\
\hline Transek 3 & $\begin{array}{l}\text { Rhizopora, } \\
\text { Avicennia }\end{array}$ & Potamididae \\
\hline Transek 4 & Rhizopora & Potamididae \\
\hline Transek 5 & Rhizopora & Potamididae, \\
\hline
\end{tabular}

\begin{tabular}{|c|c|c|}
\hline & & Acypopidae \\
\hline Transek 6 & $\begin{array}{l}\text { Rhizopora, } \\
\text { Mucronata }\end{array}$ & $\begin{array}{l}\text { Potamididae, } \\
\text { Acypopidae }\end{array}$ \\
\hline Transek 7 & $\begin{array}{l}\text { Rhizopora, } \\
\text { Avicennia, } \\
\text { Mucronata }\end{array}$ & Potamididae \\
\hline Transek 8 & $\begin{array}{l}\text { Rhizopora, } \\
\text { Avicennia, } \\
\text { Mucronata }\end{array}$ & $\begin{array}{l}\text { Potamididae, } \\
\text { Acypopidae, } \\
\text { Gobidae }\end{array}$ \\
\hline Transek 9 & $\begin{array}{l}\text { Rhizopora, } \\
\text { Mucronata }\end{array}$ & Potamididae \\
\hline Transek 10 & $\begin{array}{l}\text { Rhizopora, } \\
\text { Avicennia }\end{array}$ & $\begin{array}{l}\text { Potamididae, } \\
\text { Acypopidae }\end{array}$ \\
\hline
\end{tabular}

Hasil observasi menunjukkan hasil identifikasi jenis mangrove dan jenis biota asosiasi. Jenis Rhizopora tercatat sebagai jenis mangrove yang paling dominan ditemukan di daerah penelitian. Terlihat pada tabel 1. bahwa Rhizopora mempunyai hubungan terhadap semua jenis biota asosiasi yang teridentifikasi. Sehingga dapat dinyatakan bahwa Rhizopora merupakan jenis vegetasi yang pengaruh penting untuk keberlangsungan ekosistem biota asosiasi pada lokasi penelitian. hasil identifikasi keseluruhan jalur transek (1-10) menujukkan nilai yang relatif sama. jalur transek 8 merupakan jalur dengan keanekaragaman yang paling tinggi sehingga jalur tersebut dapat di jadikan acuan dalam pembahasan. Jalur transek yang sudah dibagi berdasarkan kerapatan hasil transformasi indeks vegetasi tersebut kemudan dibagi kedalam beberapa segmen guna mengobservasi biota asosiasi yang terdapat pada masing-masing jenis vegetasi mangrove. Hasil pengamatan setiap segmen pada salah satu jalur transek ditunjukkan pada gambar 5 .

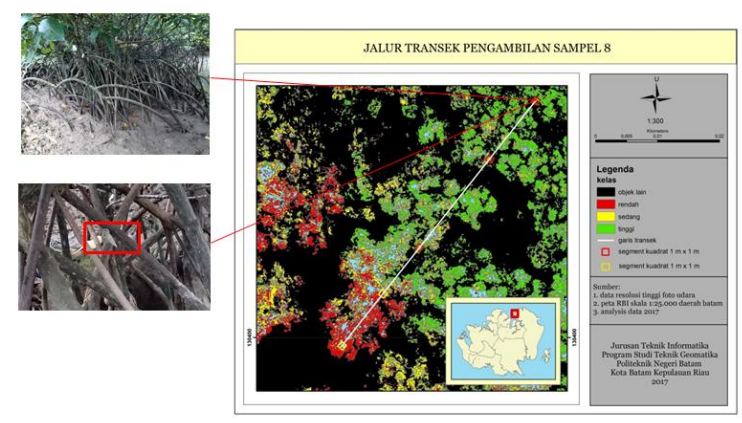



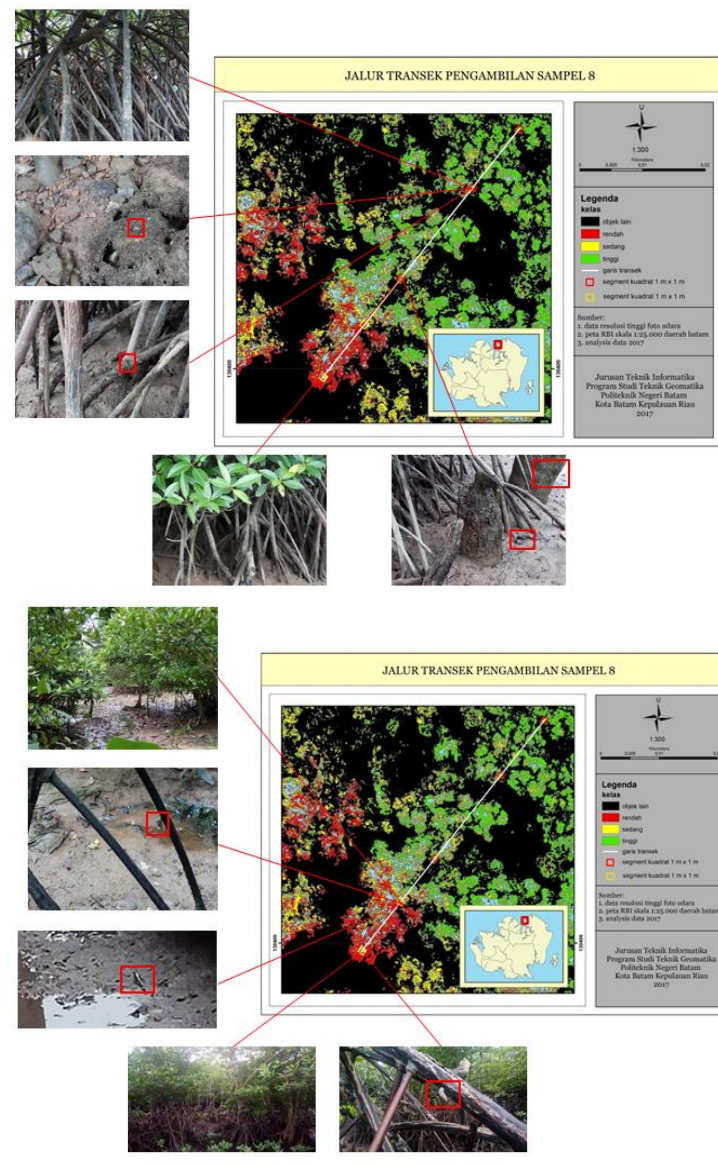

JALUR TRANSEK PENGAMBLLAN SAMPELL 8
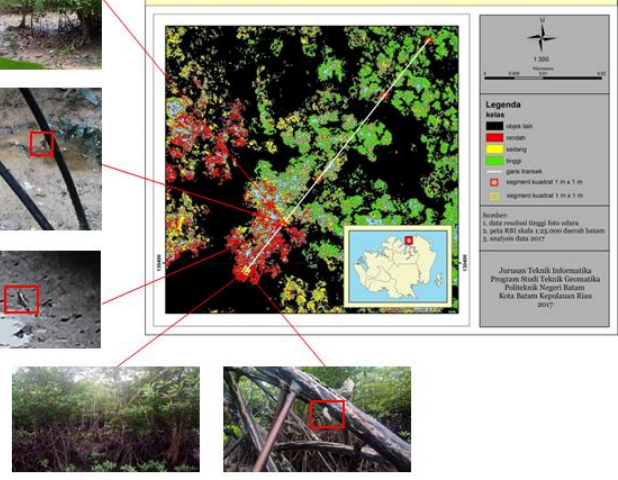

Gambar 5. Segmen observasi jalur transek 8

Hasil observasi biota asosiasi pada segmen pertama terlihat jenis mangrove yang teridentifikasi adalah jenis Rhizopora sedangkan untuk jenis biota asosiasi yang teridentifikasi adalah Potamididae. adapun untuk segmen ke 2 dan 3, jenis mangrove yang teridentifikasi relatif sama dengan segmen 1 , akan tetapi untuk jenis biota teridentifikasi terdapat 2 jenis yaitu Ocypodidae dan Potamididae. untuk ke 4 dan 5 yang merupakan daerah dengan vegetasi kerapatan rendah dengan jenis mangrove yang teridentifikasi yaitu Avencennia, Mucronata,dan Rhizopora adapun jenis biota yang teridentifikasi untuk segmen ke 4 yaitu Potamididae,Ocypopidae, dan Gobiidae sedangkan untuk segmen ke 5 yaitu hanya Potamididae. Jenis biota Gobiidae, teridentifikasi dikarenakan jenis biota tersebut memiliki interaksi terhadap lumpur serta sinar matahari oleh karena itu pada jalur transek ke8 jenis biota tersebut ditemukan dalam segmen ke 4. Hutan mangrove dari konversi kerapatan transformasi indeks vegetasi dihasilkan hasil identifikasi potensi hutan mangrove di kawasan pantai bale - bale nongsa diketahui bahwa mangrove yang terdapat disana masih dalam kondisi sangat potensial (masih dalam kondisi yang bagus) dilihat dari masih tingginya kerapatan vegetasi hutan mangrove yang terdapat di lokasi tersebut.

\section{SIMPULAN}

Hasil proses identifikasi dapat disimpulkan bahwa, jenis mangrove yang paling dominan ditemukan di pesisir bale-bale adalah mangrove Rhizopora. Dalam kawasan tutupan vegetasi Rhizopora, terdapat beberapa jenis biota asosiasi yang teridentifikasi yaitu Ocypodidae, Gobiidae, dan Potamididae namun, secara keseluruhan biota Potamididae tercatat sebegai biota yang paling dominan ditemukan. sedangkan untuk vegetasi mangrove yang lain, biota asosiasi yang teridentifikasi cederung sama dengan jenis mangrove Rhizopora, sehingga dapat disimpulkan bahwa semua jenis mangrove yang teridentifikasi memiliki hubungan yang nyata terhadap biota aosiasi yang teridentifikasi akan tetapi jika ditinjau dari segi jumlah, mangrove Rhizopora menjadi jenis yang paling berpengaruh untuk keberlangsungan ekosistem (Ocypodidae, Gobidae, Potamididae). 


\section{Kepustakaan}

Danoedoro, P. (2012). Pengantar penginderaan jauh digital. Penerbit Andi, Yogyakarta.

Anurogo, W., Murti, S. H., \& Khakhim, N. (2015). Analisis Perubahan Hutan Mangrove Dalam Penentuan Kawasan Rehabilitasi Dan Perubahan Stok Karbon Menggunakan Data Penginderaan Jauh (Di Teluk Banten, Serang Provinsi Banten) (Doctoral dissertation, Universitas Gadjah Mada).

Lillesand, T. M., \& Kiefer, R. W. (1997). Penginderaan Jauh dan Interpretasi Citra. Penerjemah: Dulbahri, Prapto Suharsono, Hartono dan Suharyadi. Editor: Sutanto.

Anurogo, W., Lubis, M. Z., Khoirunnisa, H., Pamungkas, D. S., Hanafi, A., Rizki, F., ... \& Lukitasari, C. A. (2017). A Simple Aerial Photogrammetric Mapping System Overview and Image Acquisition Using Unmanned Aerial Vehicles (UAVs). Journal of Applied Geospatial Information, 1(01), 11-18.

Campbell, J. L. (2004). Institutional change and globalization. Princeton University Press.

Kuenzer, C., Bluemel, A., Gebhardt, S., Quoc, T. V., \& Dech, S. (2011). Remote sensing of mangrove ecosystems: A review. Remote Sensing, 3(5), 878-928.

Lubis, M. Z., Taki, H. M., Anurogo, W., Pamungkas, D. S., Wicaksono, P., \& Aprilliyanti, T. (2017, December). Mapping the Distribution of Potential Land Drought in Batam Island Using the Integration of Remote Sensing and Geographic Information Systems (GIS). In IOP Conference Series: Earth and Environmental Science (Vol. 98, No. 1, p. 012012). IOP Publishing.

Rizki, F., Situmorang, A. D. L., Wau, N., Lubis, M. Z., \& Anurogo, W. (2017). Mapping Of Vegetation And Mangrove Distribution Level In Batam Island Using SPOT-5 Satellite Imagery. Journal of Geoscience, Engineering, Environment, and Technology, 2(4), 264-267.

Vo, Q. T., Oppelt, N., Leinenkugel, P., \& Kuenzer, C. (2013). Remote sensing in mapping mangrove ecosystems-An object-based approach. Remote Sensing, 5(1), 183-201.

Anurogo, W., \& Lubis, M. Z. (2018). Modified Soil-Adjusted Vegetation Index In
Multispectral Remote Sensing Data for Estimating Tree Canopy Cover Density at Rubber Plantation. Journal of Geoscience, Engineering, Environment, and Technology, $3(1), 15-24$. 